Int. J. Electrochem. Sci., 14 (2019) $4769-4780$

\title{
Synthesis and Characterization of Hexagonal Prism like Zinc Oxide for Electrochemical Determination of Gallic Acid in Wine Samples
}

\author{
Kesavan Ganesh ${ }^{1}$, Allen Joseph Anthuvan ${ }^{2}$, Shen-Ming Chen ${ }^{1, *}$, Kumuthini Rajendran ${ }^{3}$, \\ Tse-Wei Chen ${ }^{1,4}$, Viswanathan Chinnuswamy ${ }^{2}$, Shih-Yi Lee ${ }^{5,}$, Wen-Han Chang ${ }^{6,7,8}$ \\ ${ }^{1}$ Electroanalysis and Bioelectrochemistry Lab, Department of Chemical Engineering and \\ Biotechnology, National Taipei University of Technology, No. 1, Section 3, Chung-Hsiao East Road, \\ Taipei 106, Taiwan, ROC. \\ ${ }^{2}$ Department of Nanoscience and Technology, Bharathiar University, Coimbatore 641 046, India. \\ ${ }^{3}$ Nanotechnology Research Centre, SRM Institute of Science and Technology, Chennai 603 203, \\ India. \\ ${ }^{4}$ Research and Development Center for Smart Textile Technology, National Taipei University of \\ Technology, Taipei 106, Taiwan, ROC \\ ${ }^{5}$ Division of Pulmonary and Critical Care Medicine, MacKay Memorial Hospital; MacKay Medicine, \\ Nursing and Management College. \\ ${ }^{6}$ MacKay Memorial College Department of Cardiology, MacKay Memorial Hospital, Taiwan. \\ ${ }^{7}$ Department of Emergency Medicine, MacKay Memorial Hospital; Institute of Mechatronic \\ Engineering, National Taipei University of Technology, Taiwan \\ ${ }^{8}$ Graduate Institute of Injury Prevention and Control, Taipei Medical University; Department of \\ Medicine, Taiwan \\ *E-mail: smchen78@ms15.hinet.net, leesyi5538@yahoo.com.tw
}

doi: $10.20964 / 2019.05 .40$

Received: 7 January 2019 / Accepted: 25 February 2019 / Published: 10 April 2019

Metal oxides have stimulated significant attention due to their potential applications in various technology and applications. In this paper, facile and novel hexagonal prism like zinc oxide (HP-ZnO) has been successfully synthesized by mechanochemical synthesis. As prepared HP-ZnO was characterized by X-ray diffraction (XRD), scanning electron microscopy (SEM), Energy-dispersive Xray spectroscopy (EDS), particle size distribution and ultraviolet visible spectroscopy (UV-vis). Moreover, the electrochemical behavior of the proposed electrode was examined by the cyclic voltammetry and amperometric techniques. The electrochemical sensor exhibited a wide linear range from 0.1 to $130 \mu \mathrm{M}$ with a trace-level detection of $0.02 \mu \mathrm{M}(\mathrm{S} / \mathrm{N}=3)$ and showed good linearity $\mathrm{R}^{2}$ $=0.9903$. This excellent electrochemical sensing ability can be attributed to good surface area, electronic conductivity and numerous active sites. The practical application of proposed electrochemical sensor was proved by successful detection of GA in wine samples. The results 
indicated that the HP- $\mathrm{ZnO}$ is promising electrochemical sensor for selective determination of GA at trace levels in real samples.

Keywords: Metal Oxides, Amperometric Method, Phenolic Compounds, Gallic Acid, Wine Samples.

\section{$\underline{\text { FULL TEXT }}$}

(C) 2019 The Authors. Published by ESG (www.electrochemsci.org). This article is an open access article distributed under the terms and conditions of the Creative Commons Attribution license (http://creativecommons.org/licenses/by/4.0/). 